\title{
Author Correction: Introducing PIONEER: a project to harness big data in prostate cancer research
}

Muhammad Imran Omar(D, Monique J. Roobol(D, Maria J. Ribal, Thomas Abbott, Paul-Michael Agapow (D), Sonia Araujo,

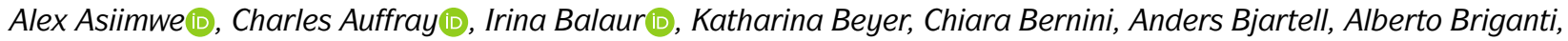
John-Edward Butler-Ransohoff, Riccardo Campi(D), Marinel Cavelaars, Bertrand De Meulder, Zsuzsanna Devecseri(D), Marc Dietrich Voss (D, Konstantinos Dimitropoulos, Susan Evans-Axelsson (D), Billy Franks, Louise Fullwood, Denis Horgan, Emma Jane Smith, Amit Kiran, Kati Kivinummi (D), Mark Lambrecht, Doron Lancet, Peter Lindgren (D), Sara MacLennan (D), Steven MacLennan (D), Maria Manuela Nogueira (D), Fredrik Moen (D), Maxim Moinat, Kishore Papineni, Christian Reich, Kristin Reiche (1), Stijn Rogiers, Claudio Sartini, Kees van Bochove (1), Femke van Diggelen (10), Mieke Van Hemelrijck, Hein Van Poppel(D), Jihong Zong, James N'Dow and The PIONEER Consortium*

Nature Reviews Urology (2020) https://doi.org/10.1038/s41585-020-0324-x Published online 27 May 2020

The originally published article contained errors in Figure 1 and did not reflect the current organization of the PIONEER consortium. The figure has been corrected in the HTML and PDF versions of the manuscript to reflect the correct organization of PIONEER.

${ }^{*}$ A list of authors and their affiliations appears online.

https://doi.org/10.1038/s41585-020-0355-3 I Published online 25 June 2020

(C) Springer Nature Limited 2020 